\title{
EVOLUTION OF A PROVINCIAL COMMITTEE ON ANAESTHETIC AND OPERATIVE DEATHS. ALBERTA 1952-1972
}

\author{
J.W.R. MCINTYRE, F.F.A.R.C.S. ${ }^{*}$
}

In September 1952 members of the Alberta Division of the Canadian Medical Association agreed to the formation of a committee whose duty it was to collect information about anaesthetic and operative deaths occurring in the province at that time. This committee has made an annual report, except for the years 1956 to 1957 , since then. My purpose is to describe the activities of this committee in the context of the evolution of medical care in Alberta.

The original committee consisted of an anaesthetist, a pathologist, and a surgeon, but it has expanded and now consists of a pathologist, two anaesthetists and two surgeons. The term of service on the committee has been variable, usually two or three years, so over the years a considerable number of physicians have been associated with the committee's activities. Such a committee is useless if it has no sources of information and indeed there were two years when it was denied access to relevant data. However, hospitals in the province are bound by law to submit the complete hospital records of patients that die to the Department of Public Health. The committee has access to these records on condition that they are returned to the Department of Public Health as soon as possible and that they are not removed from the College of Physicians and Surgeons, photocopied, or circulated to physicians outside the committee. Strict attention is paid to the confidentiality of all information obtained from these hospital records.

The committee concerned itself with the records of patients that had died within seventy-two hours of anaesthesia or surgery. Each record was scrutinized by a member of the committee and if it was believed to merit further discussion with other members the record or an abstract was used for this purpose. At times quite elaborate classifications have been used to categorize the data obtained, but over the years each death has been classified according to whether death was believed to be "inevitable," "fortuitous," "possibly preventable" or "unassessable." An inevitable death was one in which the initial state of the patient precluded the likelihood of life saving treatment. A fortuitous death was one in which the appropriate use of established techniques of medical care failed to be associated with the recovery of the patient. A possibly preventable death was a classification made with the benefit of hindsight and not necessarily implying blame. The available details of the situation indicated that appropriate techniques of medical care might not have been applied. A case was not classified as possibly preventable unless either the documented medical care was clearly inappropriate or if the records did not contain evidence of the application of such medical care as

\footnotetext{
"Department of Anaesthesia, University of Alberta, Edmonton, Alberta.
} 


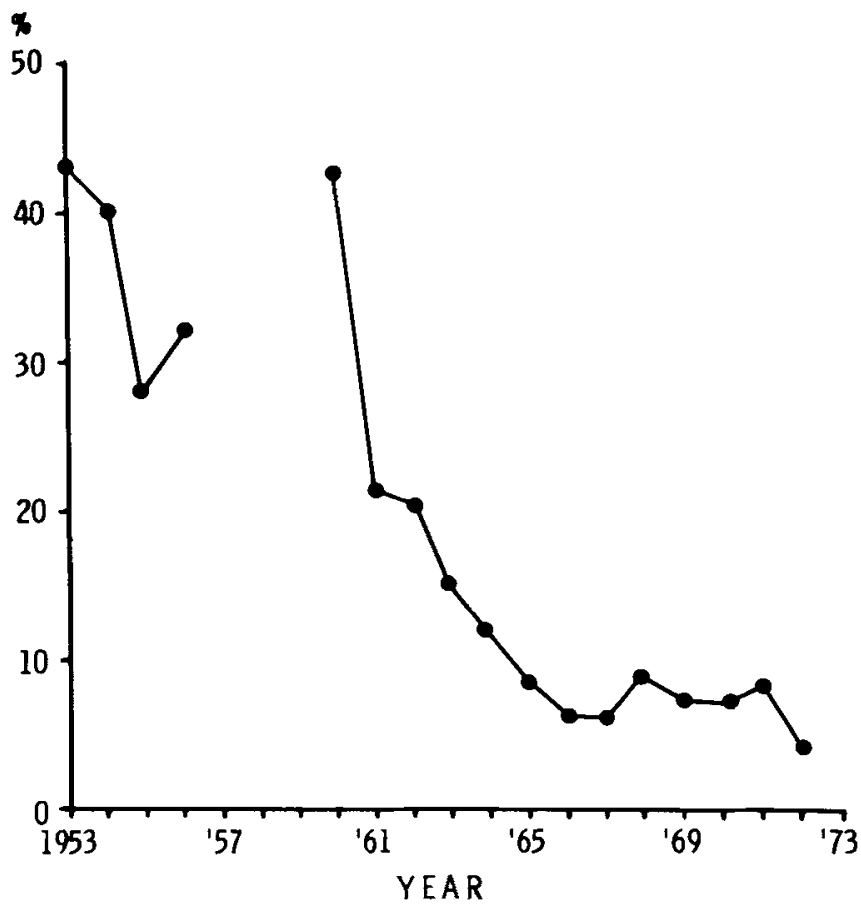

Ficure 1. The annual percentage of the classifiable records that were classified "possibly preventable."

appeared to have been necessary. The criteria of medical care applied were those of diagnosis and treatment outlined in standard current text books. Unassessable cases were those for which the details supplied were so meagre or so illegible that no other classification could be entertained.

A distinction between anaesthetic and operative deaths was not made during the last few years, because these designations implied responsibility rather than reason for the death and there is considerable variation in responsibility for patient care under various situations.

The classification of particular interest to the committee was "possibly preventable." In Figure 1 is displayed the year by year fluctuations in the number of cases so classified and the proportion that they represent of the total number of classifiable case records made available to the committee. These fluctuations are apparent changes based on the perusal and classification of hospital records by physicians. How truly do these apparent changes represent the true progress of events? There are several reasons for questioning their validity. Firstly, the drawing of conclusions regarding the quality of medical care from medical records kept in the usual manner assumes that the records describe accurately the care received by the patient and that the quality of care is indeed indicated by the records. These assumptions have been questioned and serious doubt has been cast on the eligibility of medical records maintained in the orthodox fashion to provide adequate criteria for quality assessment, ${ }^{1,2}$ though they have been con- 
sidered adequate for this purpose. ${ }^{3}$ Such criticism may not apply to the well kept operating room anaesthetic record in which successive problems and action taken during an anaesthetic are often clearly defined. Other reasons for doubting the validity of comparing the annual incidence of possibly preventable deaths are changes in the application of criteria used for classification. Also there may have been alteration in total population and population distribution as well as changes in the character and distribution of surgery being performed. In view of all these variables no valid statistical comparison can be made between each year's incidence of possibly preventable cases. However, whatever the reason may be, there appears to have been a marked reduction in the incidence of possibly preventable deaths during the first ten years of the committee's function and during recent years possibly preventable deaths have continued to occur with little change in their annual incidence.

Tables I and II present the cases classified as "possibly preventable" anaesthetic deaths reported in 1953.4 The cause of death was most often associated with some respiratory derangement. Acute cardiac arrest also figures prominently. In only four of the cases was a neuromuscular blocking agent used and in none of these did it apparently contribute to the patient's death.

Table III shows the cases classified in 1972 as possibly preventable. It will be seen that the immediate postoperative period is still a hazardous time for patients. The individual case reports are similar to those documented in other studies of death associated with anaesthesia and surgery. ${ }^{4-10}$ Scrutinizing the records of patient care and bearing in mind the criteria for the classification of "possibly preventable," that is that the available details of the situation indicated that medical care was clearly inappropriate or, that evidence of the application of such medical care as appeared to have been called for was lacking, it is possible that in some instances the committee was dealing with a problem of poor medical records rather than one of questionable medical care. However, there were cases in which the clearly documented care provided appeared to be inconsistent with current practise. In addition there were a number of other cases that though classified as "fortuitous deaths" might well have been classified as "possibly preventable." The information in the records did not clearly fulfill the criteria for a "possibly preventable" classification but left doubt that optimum medical care had been provided. This does not prove that optimum medical care was not provided but it raises the questions of whether sustained good medical care can be provided without good records and whether a situation in which written evidence of care does not exist can continue in the present climate of medical practise. Certainly elaborate and factual case records are invaluable to the physician in any involvement he may have with medico-legal questions. Thus it appears that possibly preventable deaths have continued to occur in the Province of Alberta during the past ten years.

At its inception the object of the first committee in Alberta was to ascertain the incidence of peroperative and postoperative deaths, but the findings indicated that some sort of action should be taken on behalf of the physicians and patients of the province. The terms of reference of the present committee probably differ little from those of its predecessors. "The committee may communicate with 
TABLE I

\begin{tabular}{lc}
\hline \multicolumn{1}{c}{ Operation } & $\begin{array}{c}\text { Anaesthetic } \\
\text { death }\end{array}$ \\
\hline Ear-nose-throat & 3 \\
Other-head \& neck & 3 \\
Thoracic & 0 \\
Gastric & 3 \\
Biliary & 2 \\
Small and large bowel & 5 \\
Hernia & 4 \\
Endoscopy & 0 \\
Orthopaedic & 1 \\
Obstetrical & 1 \\
Gynaecological & 2 \\
Neurosurgical & 0 \\
Others & 2 \\
& -26 \\
\hline
\end{tabular}

TABLE II

Cause of Death in 26 Cases Classified as Anaesthetic Deaths

1. Anaesthetic overdose with respiratory and/or circulatory failure 10

2. Respiratory obstruction during anaesthesia

3. Respiratory obstruction following anaesthesia

4. Regurgitation or vomiting with aspiration

5. Convulsions during ether anaesthesia

6. Acute cardiac arrest, probably due to

(a) Movement of the patient

(b) Reflex disturbances with possible hypoxia and/or hypercarbia 2

(c) Ventricular fibrillation due to drug incompatibility

(d) Inadequate ventilation

TABLE III

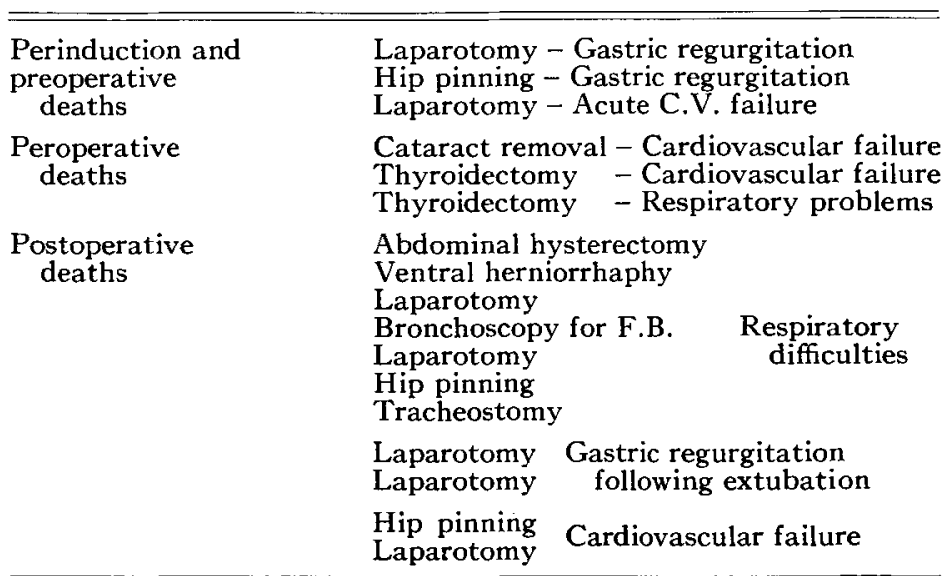


physicians for more information regarding a death. The committee may also provide confidential retrospective analysis to physicians where such action is indicated. However, where a case warrants admonition, advice regarding refresher courses, discipline, or where competence is questioned, it should be referred to the Board of Directors of the Alberta Medical Association for action." The actions taken by early committees are shrouded in mystery - which is as it should be. However, the apparent improvement that occurred during the period 1953-1963 must surely have been at least partially due to the implementation of measures described in the Canadian Anaesthetists' Society Journal of 1955. These were the provision of retrospective analyses to physicians, the publication of useful information in the Alberta Medical Bulletin, and the circulation of visiting speakers in the province. However, there appears to have been little change in affairs during the last ten years and the fact is that the recommendations presented to the Annual Meeting of the Alberta Division of the Canadian Medical Association in $1972^{11}$ are startlingly similar to those recommendations appearing in the Alberta Medical Bulletin in 1953.12 Thus, although the objectives of the Committee on Anaesthetic and Operative Deaths do not need to be redefined, the method by which it attempts to achieve them does. The supply of hospital records from the Department of Health is satisfactory. However, the total number of possibly preventable deaths occurring in the province and their probable cause cannot be determined unless there are changes in the presentation of data in the medical records of patients that die. The recommendation that a narrative summary of anaesthesia events be incorporated in the records ${ }^{11}$ may well be insufficient, and a protocol designed to acquire relevant data may be necessary. The Alberta Division of the Canadian Anaesthetists' Society has given support to the concept of an appropriately designed protocol becoming a necessary part of the patient's documentation if death has occurred within 72 hours of operation. The implementation of more radical changes such as those suggested by Weed ${ }^{1,13}$ may not be necessary but there is no doubt about the fact that medical records should be legible and there are indeed problems in this area. The techniques that have been used to draw the attention of physicians engaged in the practise of anaesthesia to potential clinical problems and methods of dealing with them appear to have reached the limit of their efficacy. Refresher Courses in Anaesthesia consisting of seminars and practical demonstrations have been available in Alberta since 1966. These have been popular and must have been of value, as must the friendly reception of casual visitors to departments of anaesthesia. However, the availability of a system by which the individual physician can rapidly assess his own theoretical knowledge while engaging in a private learning process has encouraging possibilities for anyone concerned with the quality of medical care. A block diagram of such a system appears in Figure 2. The system can be utilized in the following manner. The two screens are to be used to depict multiple choice questions and patient management problems. Photographs of patients, equipment, or graphic data can be displayed and an audio component may be added if necessary. The individual proceeds sequentially through the programme by using the light pen or key-board in the manner that seems appro- 


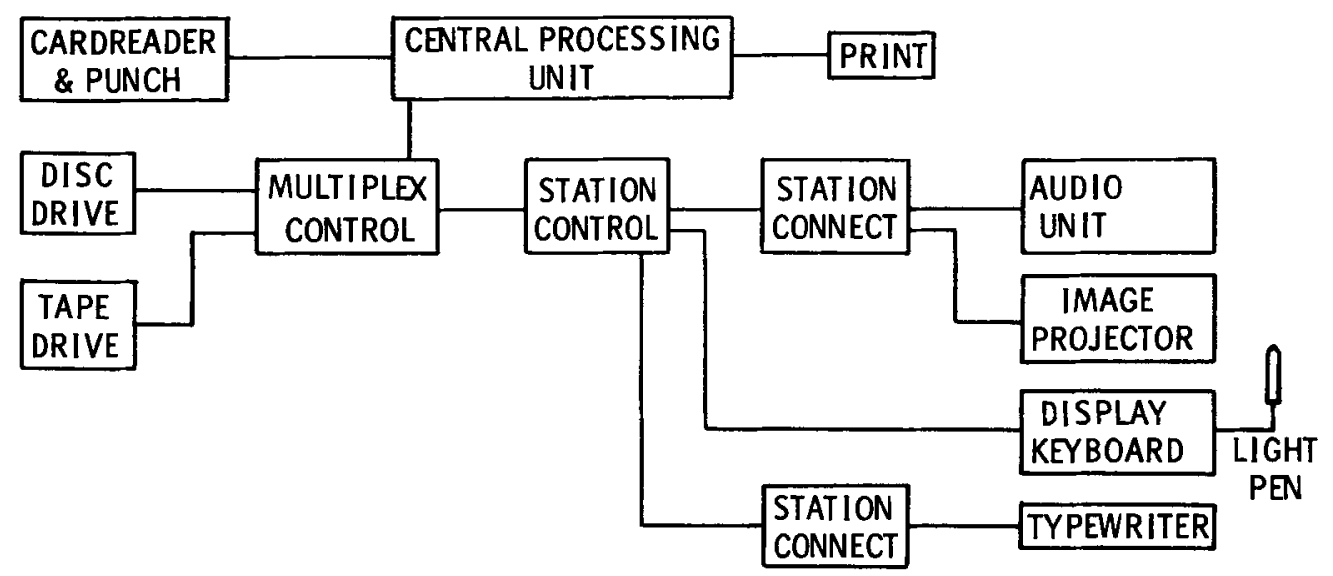

FIgUre 2. The IBM 1500 audio-visual instructional system in use at present.

priate to him. According to the wishes of the designer of the programme included in it are explanations to the individual about why his selected answer in the programme is considered to be incorrect, or encouragement if the answer selected by the individual is correct. Immediately the test programme has been completed the individual's score can be made available to him. Such a programme for anaesthesia has been designed at the University of Alberta but the scoring of such programmes is still a matter of controversy and investigation. Questions to which there is a simple right or wrong answer present no problem, but patient management problems are more complicated. There may be professional disagreement about what should be done or what order a sequence of events should follow, so the opinion of the programme designer is insufficient even if a more complex system of scoring is devised. One method which is presently under study is to have a number of experts in a specialty participate in a test programme and then formulate a scoring system for that programme suitably loaded according to the frequency of certain answers. Answers that deviate markedly from any scoring system that has been established will raise doubts in the minds of programme designers who themselves will be thus subjected to a potential learning process.

In conclusion it seems that an accurate assessment of "possibly preventable" deaths associated with anaesthesia and surgery can only occur if radical changes take place in certain aspects of medical records. Improvement in patient care will be the result of the acquisition and application of knowledge. Computerized audio-visual teach/test systems could play a vital role in the acquisition of knowledge. Its acquisition and its application depend on the personal motivation that lurks in all physicians. At this point it should be noted that about 20 years ago the late Dr. C.M. Learmonth and Dr. M. Yates established the first Committee on Anaesthetic and Operative Deaths in the Province of Alberta. The first committee consisted of Dr. E.A. Gain (Anaesthetist), Dr. H.L. Richard (Surgeon), and Dr. S. Hanson (Pathologist). These men should be remembered for their pioneer work. 


\section{SUMMARY}

Since 1953 the complete case records of patients dying after anaesthesia and surgery have been submitted by the Department of Health of the Province of Alberta to a Committee of the Alberta Medical Association. This committee consisted of representatives of anaesthesia, surgery and pathology who reviewed and classified the records. In the classification was a category for "possibly preventable" deaths. During the first ten years of the committee's activity there was a reduction in the proportion of cases so classified. How much the committee influenced this change cannot be ascertained but it appears that during the last ten years there has been no further improvement. One conclusion reached is that present methods of disseminating knowledge of current practise of anaesthesia and encouraging its use in Alberta has reached its maximum efficiency. A computerized teach/test audio-visual instruction system for which anaesthesia programmes have been designed is described. A second conclusion is that the real incidence of "possibly preventable" deaths cannot be determined because of the character of the data available in the medical records that reach the committee.

\section{RÉSUMÉ}

Depuis 1953, les dossiers complets des malades morts à la suite d'anesthésie et de chirurgie ont été soumis à un comité de l'Association Médicale de l'Alberta par le département de la Santé de la Province d'Alberta. Les membres de ce comité comptaient des anesthésistes, des chirurgiens et des pathologistes; ils ont étudié et classifié les dossiers. Dans cette classification, il y avait une catégorie pour " les morts évitables possibles ». Durant les dix premières années de l'activité du comité, le nombre des cas de cette catégorie a diminué. Jusquà quel point, le comité a influencé ce changement, on ne peut pas l'assurer, mais il semble qu'au cours des. dix dernières années il n'y a pas eu d'amélioration. Il est permis de conclure que les méthodes actuelles de disséminer la connaissance de la pratique courante de l'anesthésie et d'encourager son usage en Alberta ont atteint leur maximum d'efficacité. Nous décrivons un système d'enseignement audio-visuel et d'évaluation placé sur ordinateur pour lequel on a adapté des programmes d'anesthésie. Une deuxième conclusion à tirer, c'est que la fréquence réelle des cas de " mort évitable possible " ne peut pas être précisée à cause du caractère des données à la disposition dans les dossiers médicaux qui parviennent au comité.

\section{REFERENCES}

1. WeEd, L.L. Quality control and the medical record. Arch. Intern. Med. 127: 101 (1971).

2. McWrtnNey, I.R. Medical audit in North America. Brit. Med. J. 2: 227 (1972).

3. Taubenhaus, L.J. The hospital record as a tool for assessment of physician postgraduate educational needs in the cardiovascular field. J. Amer. Ger. Soc. 27: 1025 (1969).

4. Gain, E.A. Anaesthetic deaths in Alberta. Canad. Anaesth. Soc. J. 2: 81 (1955).

5. Deaths associated with anaesthesia - report on 400 cases. Presented by the Committee of Investigation to the Council of the Association of Anaesthetists of Great Britain and Ireland in June 1949. Anaesthesia 7: 200 (1952).

6. BEECHER, H.K. \& TODD, D.P. A study of the deaths associated with anaesthesia and surgery. Annals of Surg. 140: 3 (1954). 
7. Edwards, George, Morton, H.J.V., Pask, E.A., \& Wylie, W.D. Deaths associated with anaesthesia. A report on 1,000 cases. Anaesthesia 11: 194 (1956).

8. Campbele, J.E., Weiss, W.A., \& Rieners, F. Evaluation of deaths associated with anesthesia: correlation of clinical, toxicologic and pathologic findings. Anesth. \& Analg. 40: 54 (1961).

9. DiNNICK, O.P. Deaths associated with anaesthesia. Anaesthesia 19: 536 (1964).

10. Special committee investigating deaths under anaesthesia. Report on 745 classified cases, 1960-1968. Med. J. of Australia 1: 573 (1970).

11. Annual report of committee on anaesthetic and operative deaths. Alberta Medical Bulletin 37: 234 (1972).

12. Annual report of committee on anaesthetic and operative deaths. Alberta Medical Bulletin 18: 15 (1953).

13. Ten reasons why Lawrence Weed is right. Editorial. New Eng. J. Med. 284: 51 (1971). 